\title{
EXISTING STEEL RAILWAY BRIDGES EVALUATION
}

\author{
Josef VIČAN ${ }^{1,{ }^{*}}$, Jozef GOCÁL ${ }^{1}$, Jaroslav ODROBIŇÁK ${ }^{1}$, Peter KOTEŠ ${ }^{1}$ \\ 1 Department of Structures and Bridges, Faculty of Civil Engineering, University of Žilina, Univerzitná \\ 8215/1, 01026 Žilina, Slovakia. \\ corresponding author: vican@fstav.uniza.sk.
}

\section{Abstract}

The article describes general principles and basis of evaluation of existing railway bridges based on the concept of load-carrying capacity determination. Compared to the design of a new bridge, the modified reliability level for existing bridges evaluation should be considered due to implementation of the additional data related to bridge condition and behaviour obtained from regular inspections. Based on those data respecting the bridge remaining lifetime, a modification of partial safety factors for actions and materials could be respected in the bridge evaluation process. A great attention is also paid to the specific problems of determination of load-caring capacity of steel railway bridges in service. Recommendation for global analysis and methodology for existing steel bridge superstructure load-carrying capacity determination are described too.
\end{abstract}

\author{
Keywords: \\ Evaluation; \\ Existing railway bridge; \\ Bridge load-carrying capacity; \\ Passage of service load; \\ Partial safety factors for loads \\ and resistances.
}

\section{Introduction}

In the period of 2013 - 14 the collective of the Department of Structures and Bridges has worked up the Guideline "Determination of load-carrying capacities of railway bridges" [1] for Slovak Railways. Therefore, the paper describes general concept and basic assumptions for evaluations of existing railway bridges and determining their load-carrying capacities based on the principles of Eurocodes.

Evaluation of existing railway bridges represents the key process of the Bridge Management Systems relevant from the viewpoint of decision-making processes. Therefore, it should be based on the reliability concept respecting the load-carrying capacity as the basic parameter of the existing bridge reliability. The existing bridge evaluation should be considered when relevant deviations from the project documentation are found, when significant deterioration from the viewpoint of bridge reliability is observed, or when the bridge exceeds its recommended design life. Concurrently, the bridge load-carrying capacity is the decision parameter for determining the passage of corresponding railway service load over the bridge.

\section{General concept of the railway bridge load-carrying capacity determination}

\subsection{General}

The concept of the above mentioned existing bridge evaluation is fully compatible with the principles of Eurocodes, so that the structure of the new Guideline is consistent with European standards. The Guideline introduces general rules of determining the load-carrying capacity of the permanent and temporary railway bridges on tracks with speed up to $200 \mathrm{~km}$ per hour with respect to different level of its accuracy. It also presents provisions for assessment of the passage of the railway service load classified into the corresponding Line Categories (LC). Concurrently, it should also be used for estimation of the load-carrying capacity of new bridge with respect to reliability level adequate to design of the new bridge without alleviations and simplifications specified only for existing bridge.

The Guideline introduces two types of the bridge load-carrying capacities. Normal load-carrying capacity $R F_{L M 71}$ is specified as a dimensionless ratio of the marginal effect of variable vertical rail traffic load satisfying relevant ultimate or serviceability limit state, to the effect caused by the LM71 in accordance with the standard [2]. The exceptional load-carrying capacity should be estimated using analysis of the existing bridge in accordance with approaches and principles presented in the 
Guideline respecting additional alleviations in comparison to normal load-carrying capacity. According to the precision of methodology used for the load-carrying capacity determination, the four categories ( $A, B, C$ and $D$ ) of load-carrying capacities are defined. A great attention is given to the estimation of the load-carrying capacity of the category $C$ and $D$, which are calculated using analysis of existing bridge based on its assessed actual condition. Considering a new bridge, its load-carrying capacity should be determined on results of its design analysis. In the case of the categories A or $B$, the determining the bridge load-carrying capacity is based on the estimation or comparative analysis.

\subsection{Actions on railway bridges}

All main principles in accordance with relevant Eurocodes for actions on bridges shall be respected. The current state, location and values of loads shall be taken into account by in-situ measurements compared to the available bridge documentation. Characteristic values of the permanent actions on existing bridges shall be considered in accordance with standard [4] respecting Annex D in standard [5], and standard [6] in cases, when the results of in-situ measurements on the bridge are allowed for. Density of material should be stipulated indirectly on the basis of standard or tabulated values or directly using specimens or samples obtained from bridge structural members.

For calculation of load-carrying capacity of existing bridge, the vertical rail traffic load represented by the LM71 according to standard [2] shall be applied with $\alpha=1.00$. Nosing force, centrifugal force, braking and acceleration forces multiplied also by $\alpha=1.00$, which shall be considered to act concurrently with the vertical rail traffic load, shall be also taken in accordance with the code [2].

Dynamic effects of the vertical rail traffic load may be considered using the dynamic factors $\Phi_{2}$ or $\Phi_{3}$ in accordance with standard [2]. Unless the relevant authority of the railways specifies, the dynamic factor, $\Phi_{3}$ shall be applied for determining the existing bridge load-carrying capacity. Disregarding the bridge deck type, redistribution of vertical and horizontal forces to the three rail support close to the acted axle forces of LM71 or other concentrated wheel loads may be considered.

To determine the design values of the effects of permanent, variable (LM71, nosing force, centrifugal force and braking and acceleration forces) and non-traffic actions on bridge (wind and thermal loads), the partial factors of load effects are used. The following values of partial factor $\gamma_{G}$ should be considered for determination of the design values of permanent load effects on existing bridges, unless more precise calculation is assumed:

- bridge structural members whose geometrical parameters were checked by measurements: $\gamma_{G}=1.20$,

- bridge structural members whose geometrical parameters were not checked: $\gamma_{G}=1.30$.

Partial factor $\gamma_{Q, L M 71}$ for the vertical and horizontal variable rail traffic load effects should be taken into account dependent on the age of bridge structural member and its planned remaining lifetime using values as follows:

- bridge structural member younger than 30 years: $\gamma_{Q, L M 71}=1.40$,

- bridge structural member older than 30 years: $\gamma_{Q, L M 71}=1.25$.

The partial factors for non-traffic load effects (wind and thermal load) should be considered by the following values dependent on the age of bridge structural member and its planned remaining lifetime:

- bridge structural member younger than 30 years: $\gamma_{Q}=1.50$,

- bridge structural member older than 30 years: $\gamma_{Q}=1.35$.

Partial factors for the load effects concerning the serviceability limit states should be taken by values of $\gamma_{F, \text { ser }}=1.0$.

There is a possibility to determine values of partial factors for load effects using the more precise approach according to articles [7], [8] given in Annex F of this Guideline in dependence on the age of bridge structural member and bridge planned remaining lifetime. This procedure should be stated by the relevant authority of the Slovak Railways. More precise approach was also presented in paper [9]. 


\section{Analysis of existing steel railway bridges}

\subsection{Material characteristics}

Characteristics of material and their design values should be specified either by means of the by-inspection verified documentation and the standards valid at the time of bridge design, or on the results of the bridge diagnostics and material tests. The guaranteed yield strength given in bridge documentation or in the standard valid at the time of bridge design may be taken as the characteristic value of steel yield strength. When the year of the bridge fabrication is known and no doubts are about the material classification (S 235, S 275 and S 355) the Table 1 could be used for estimation of steel characteristics. The design cross-sectional and member resistances for ultimate limit state (without fatigue) verification should be determined using values of design yield and ultimate strengths obtained by dividing the characteristic values by partial factor $\gamma_{M i}$, which may be also taken from Table 1 .

Unless bridge documentation is available or there are doubts about the quality of the material used, results of diagnostic techniques and material tests should be applied. In this case, the properties of steel material shall be determined according to standards [5], [6] or relevant provisions in Guideline. The values of partial factors for resistances $\gamma_{M i}$ should be calculated using the more precise approach (see standards [5], [6]).

Unless more precise methods are considered for determining the values of partial factors, the values from Table 1 may be used or the procedures given in Annex F of the Guideline may be applied using statistical parameters of steel obtained by tests.

Unless the material for rivets and bolts used in steel bridge structure constructed before 1968 is known, the characteristic values of their material properties may be considered according to Table 2 in dependence on the quality of materials of connected elements. The value of the partial factor $\gamma_{M 2}$ for resistance of connections may be taken from Table 1. Characteristic values of material properties of rivets and bolts and their partial factors for resistance in steel structures constructed after 1968 may be considered in accordance with standard [12]. Rivets in steel structures of existing bridges constructed before 1905 can be considered to be made of wrought iron. Characteristic values of the material yield and ultimate strength and value of the partial factor $\gamma_{M 2}$ for resistance of connection can be taken from Table 1. 
Table 1: Recommended material characteristics of steel and values of partial factors for member and cross-sectional resistances.

\begin{tabular}{|c|c|c|c|c|c|c|c|c|}
\hline \multirow[b]{2}{*}{ Year of bridge construction } & \multicolumn{2}{|c|}{ Steel material/ grade } & \multirow{2}{*}{$\begin{array}{c}\text { Allowable stress } \\
\sigma_{a d m} \\
{[\mathrm{MPa}]}\end{array}$} & \multirow{2}{*}{$\begin{array}{c}\text { Yield strength } \\
f_{y} \\
{[\mathrm{MPa}]}\end{array}$} & \multirow{2}{*}{$\begin{array}{c}\text { Ultimate } \\
\text { strength } \\
f_{u} \\
{[\mathrm{MPa}]} \\
\end{array}$} & \multirow[b]{2}{*}{$\gamma_{M O}$} & \multirow[b]{2}{*}{$\gamma_{M 1}$} & \multirow[b]{2}{*}{$\gamma_{M 2}$} \\
\hline & & $\begin{array}{c}\text { Thickness } \\
{[\mathrm{mm}]}\end{array}$ & & & & & & \\
\hline before 1895 & \multicolumn{2}{|c|}{ wrought iron } & 130 & 210 & 340 & 1.10 & 1.20 & 1.30 \\
\hline \multirow{2}{*}{$1895-1904$} & \multicolumn{2}{|c|}{ wrought iron } & 130 & 210 & 340 & 1.10 & 1.20 & 1.30 \\
\hline & \multicolumn{2}{|c|}{ mild steel } & 140 & 230 & 360 & 1.10 & 1.20 & 1.30 \\
\hline $1905-1937$ & \multicolumn{2}{|c|}{ mild steel } & 140 & 230 & 360 & 1.10 & 1.20 & 1.30 \\
\hline \multirow{2}{*}{$1938-1950$} & \multicolumn{2}{|c|}{37 (S 235) } & 140 & 230 & 360 & 1.10 & 1.20 & 1.30 \\
\hline & \multicolumn{2}{|c|}{52 (S 355) } & 195 & 335 & 490 & 1.10 & 1.25 & 1.30 \\
\hline \multirow{4}{*}{$1951-1968$} & \multirow{2}{*}{37 (S 235) } & $t \leq 25$ & 140 & 230 & 360 & 1.10 & 1.20 & 1.30 \\
\hline & & $>25$ & 130 & 210 & 340 & 1.10 & 1.20 & 1.30 \\
\hline & \multirow{2}{*}{52 (S 355) } & $\leq 16$ & 210 & 360 & 510 & 1.10 & 1.25 & 1.30 \\
\hline & & $>16$ & 200 & 340 & 490 & 1.10 & 1.25 & 1.30 \\
\hline \multirow{3}{*}{$1969-1985$} & \multirow{2}{*}{37 (S 235) } & $\leq 25$ & & 235 & 360 & \multirow{3}{*}{1.00} & \multirow{3}{*}{1.10} & \multirow{3}{*}{1.25} \\
\hline & & $>25$ & & 215 & 360 & & & \\
\hline & 52 (S 355) & $\leq 50$ & & 355 & 510 & & & \\
\hline \multirow{4}{*}{$1986-1998$} & \multirow{2}{*}{37 (S 235) } & $\leq 25$ & & 235 & 360 & \multirow{4}{*}{1.00} & \multirow{4}{*}{1.10} & \multirow{4}{*}{1.25} \\
\hline & & $>25$ & & 215 & 360 & & & \\
\hline & \multirow{2}{*}{52 (S 355) } & $\leq 25$ & & 355 & 510 & & & \\
\hline & & $>25$ & & 335 & 470 & & & \\
\hline \multirow{6}{*}{$1998-2010$} & S 235 & $\leq 40$ & & 235 & 360 & \multirow{6}{*}{1.00} & & \\
\hline & S 235 & $40<t \leq 80$ & & 215 & 360 & & & \\
\hline & S 275 & $\leq 40$ & & 275 & 430 & & 11 & 125 \\
\hline & S 275 & $40<t \leq 80$ & & 255 & 410 & & 1.10 & 1.20 \\
\hline & S 355 & $\leq 40$ & & 355 & 510 & & & \\
\hline & S 355 & $40<t \leq 80$ & & 335 & 470 & & & \\
\hline
\end{tabular}

Table 2: Characteristic values of materials for rivets and bolts.

\begin{tabular}{|c|c|c|c|c|}
\hline \multirow{3}{*}{ Material characteristics } & \multicolumn{2}{|c|}{ Rivets } & \multicolumn{2}{c|}{ Bolts } \\
\cline { 2 - 5 } & \multicolumn{3}{|c|}{ in structures made of material with yield strength } \\
\cline { 2 - 5 } & $f_{v} \leq 300 \mathrm{MPa}$ & $f_{v}>300 \mathrm{MPa}$ & $f_{v} \leq 300 \mathrm{MPa}$ & $f_{v}>300 \mathrm{MPa}$ \\
\hline$f_{y}[\mathrm{MPa}]$ & 200 & 245 & 300 \\
\hline$f_{u}[\mathrm{MPa}]$ & 310 & 440 & \multicolumn{2}{c|}{500} \\
\hline
\end{tabular}

\subsection{Global analysis}

To enable the more precise approximation of the actual bridge behaviour and allowing for the effects of the possible imperfections or damages of the structural members, the spatial computational models should be used for global analyses of steel railway bridges. Elastic methods shall be used to determine internal forces and moments of the bridge structural elements. Usually, the elastic first order method is applied using the initial structural shape with respect of the relevant criterion for application of the first order theory (see standard [10]). In the global analysis of existing bridge, its actual condition shall be respected. The failures and deteriorations including relevant imperfections of structural members or bridge parts shall be implemented into the bridge computational model by the appropriate way to allow for effects of them on the final bridge response to all loads. In addition, the effects of the failures and deteriorations shall be considered in calculations of the bridge structural member and cross-sectional resistances. The shape and size of imperfection significantly affecting the member 
load-carrying capacity is recommended to be obtained by means of measurements on the real bridge structure, especially in the case of riveted bridge structural elements where the effects of residual stresses is negligible. The following damages and imperfections should be considered in the global analysis:

- noticeable global buckling of the member systems creating one unit (arch bridges, compression chord of truss bridges with open arrangement),

- significant deformations of the structural members and parts of bridge steel structures due to vehicle impacts,

- absenting structural members or bridge parts,

- significantly corroded cross-sections of structural members.

In the case of bridges with welded cross-sections, the equivalent geometrical imperfections according to standards $[10,11]$ may be used. The assumed imperfection shape of the steel bridge structural member or part is recommended to be derived from the shape of elastic critical buckling mode of a structure as a unique global and local imperfection. The amplitude of this imperfection should be determined by means of 5.3.2 in the standard [10]. In the case of plated structures, the shapes and amplitudes of equivalent geometrical imperfections may be determined in accordance with Annex $C$ in standard [11]. When method of equivalent member for resistance verification according to standard [10] is used, local imperfections of cross-sections and members should be allowed for into their resistances using relevant reduction factors for flexural, lateral-torsional or plate buckling.

In the global analysis of bridge plated structures, the effect of shear lag shall be taken into account. Unless more precise approach is used, the effect of this phenomenon may be considered by means of an effective width. The effect of plate buckling in the elastic global analysis may be allowed for by effective cross-sectional areas of the elements in compression.

When the load-carrying capacity of the bridge structure should be significantly limited by resistance of very slender compression member, there is a possibility to omit this member from global analysis upon reaching their compression resistance, provided that the elastic redistribution of internal forces and moments is admissible and the remaining part of the structure is allowable to carry the acting loads.

\subsection{Determination of load-carrying capacity for ultimate limit states}

The reliability of existing bridge structural elements shall be verified and their load-carrying capacities shall be determined using partial safety factors method, by which the fulfilment of conditions of relevant ultimate limit state regarding the appropriate design situation shall be assessed.

Welded cross-sections should be classified with respects to slenderness of their partial parts in accordance with Table 2 in the standard [10]. Longitudinally stiffened compression webs and flanges should be classified respecting the rules defined in the standard [11]. For classification of the riveted cross-sections, the widths of relevant cross-sectional parts defined in Fig. 1 should be taken into account. Except for transversal direction, the classification should also respects the rivet distances parallel to the acting compression stress. Due to unknown behaviour of riveted cross-sections in plastic area of stressing, the elastic resistance should only be considered for assessment of the crosssectional resistance.
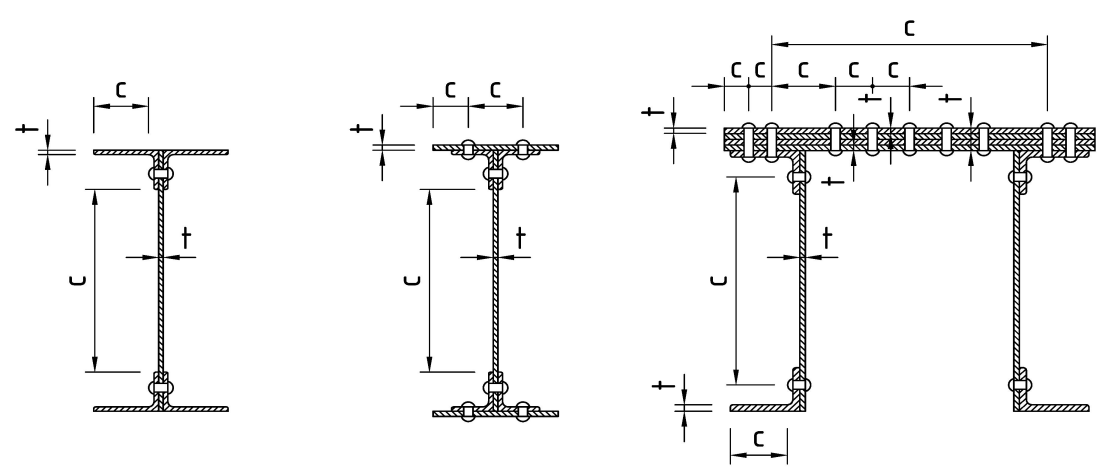

Fig. 1: Definition of widths for classification of riveted cross-sections. 
From the ultimate limit states viewpoint, the load-carrying capacity of the bridge structural member should be expressed by the general equation defining the Rating Factor $\left(R F_{L M 71}\right)$ of variable traffic load represented by the LM71 in the form as follows:

$R F_{L M 71}=\left(R_{d}-\sum_{i=1}^{n-1} E_{r s, E d, i}\right) / E_{L M 71, E d}$,

where:

$R_{d} \quad$ is the cross-sectional resistance of the bridge structural member,

$E_{L M 71, E d}$ represents design value of vertical variable rail traffic load effects represented by the LM71 including dynamic factors,

$\Sigma E_{r s, E d, i}$ is design, combination or group values of the other load effects acting concurrently with the vertical rail traffic load.

The load-carrying capacity of cross-sections classified into the classes 1, 2 and 3 subjected to combination of bending, shear and normal force, provided that shear force $V_{E d}$ fulfils the following condition

$\eta_{3}=\frac{V_{E d}}{V_{p l, R d}} \leq 0,5 \quad$ resp. $\quad \bar{\eta}_{3}=\frac{V_{E d}}{V_{b w, R d}} \leq 0,5$

should be determined using equation as follows:

$$
\begin{aligned}
& R F_{L M 71}=\frac{1-\eta_{1, r s}}{\eta_{1, L M 71}}, \text { and } \\
& \eta_{1, r s}=\frac{N_{r s, E d}}{A \cdot f_{y} / \gamma_{M 0}}+\frac{M_{y, r s, E d}}{W_{e l, y} \cdot f_{y} / \gamma_{M 0}}+\frac{M_{z, r s, E d}}{W_{e l, z} \cdot f_{y} / \gamma_{M 0}}, \\
& \eta_{1, L M 71}=\frac{N_{L M 71, E d}}{A \cdot f_{y} / \gamma_{M 0}}+\frac{M_{y, L M 71, E d}}{W_{e l, y} \cdot f_{y} / \gamma_{M 0}}+\frac{M_{z, L M 71, E d}}{W_{e l, z} \cdot f_{y} / \gamma_{M 0}},
\end{aligned}
$$

where:

$V_{p l, R d} \quad$ is the design plastic shear resistance,

$V_{b w, R d} \quad$ is the design shear resistance respecting the web shear buckling,

$N_{L M 71, E d}, M_{y, L M 71, E d}, M_{z, L M 71, E d}$ are the design values of internal forces and moments caused by the vertical variable rail traffic load represented by LM71 including dynamic factors,

$N_{r s, E d}, M_{y, r s, E d}, M_{z, r s, E d} \quad$ are the design, combination or group values of the internal forces and moments due to other load effects acting concurrently with the vertical rail traffic load,

$A, W_{e l, y}, W_{e l, z} \quad$ are the cross-sectional characteristics,

$\gamma_{M 0} \quad$ is the partial safety factor for the cross-sectional resistance.

Because of dependence of the shear force $V_{E d}$ on the load-carrying capacity in equation (2), the calculation of $R F_{L M 71}$ should run using an iterative approach. When for shear force $V_{E d}>V_{p l, R d}\left(V_{b w, R d}\right)$, i.e. $\eta_{3} \geq 0.5$ or $\bar{\eta}_{3} \geq 0.5$ respectively is valid, then verifying the elastic cross-sectional resistance of classes 1,2 and 3 and determination of their load-carrying capacities $R F_{L M 71}$ should be performed by means of the following quadratic equation

$$
4 \cdot k \cdot Z_{L M 71}^{2} \cdot \eta_{3, L M 71}+Z_{L M 71} \cdot\left(\eta_{1, L M 71}+8 \cdot k \cdot \eta_{3, L M 71} \cdot \eta_{3, r s}-4 \cdot k \cdot \eta_{3, L M 71}\right)+
$$




$$
\begin{aligned}
& +\eta_{1, r s}+4 \cdot k \cdot \eta_{3, r s}^{2}-4 \cdot k \cdot \eta_{3, r s}+k-1=0 \text { or } \\
& 4 \cdot k \cdot Z_{L M 71}^{2} \cdot \bar{\eta}_{3, L M 71}+Z_{L M 71} \cdot\left(\eta_{1, L M 71}+8 \cdot k \cdot \bar{\eta}_{3, L M 71} \cdot \bar{\eta}_{3, r s}-4 \cdot k \cdot \bar{\eta}_{3, L M 71}\right)+ \\
& +\eta_{1, r s}+4 \cdot k \cdot \bar{\eta}_{3, r s}^{2}-4 \cdot k \cdot \bar{\eta}_{3, r s}+k-1=0 \quad \text { respectively }
\end{aligned}
$$

where $\eta_{1, r s}$ and $\eta_{1, L M 71}$ are defined by the equations (4) and (5) and

$$
\begin{aligned}
& \eta_{3, r s}=\frac{V_{r s, E d}}{V_{p l, R d}}, \bar{\eta}_{3, r s}=\frac{V_{r s, E d}}{V_{b w, R d}}, \eta_{3, L M 71}=\frac{V_{L M 71, E d}}{V_{p l, R d}}, \\
& \bar{\eta}_{3, L M 71}=\frac{V_{L M 71, E d}}{V_{b w, R d}}, k=1-\left(\frac{M_{f, N, R d}}{M_{p l, N, R d}}\right)
\end{aligned}
$$

$V_{L M 71, E d}$ is the design shear force caused by the vertical variable rail traffic load represented by LM71 including dynamic factors,

$V_{r s, E d} \quad$ is the design, combination or group values of shear force due to other load effects acting concurrently with the LM71,

$M_{f, N, R d}$ is the design plastic moment resistance of the cross-section consisting of effective areas of flanges (with respect of shear lag) reduced due to effect of normal force $N_{E d}$ according to 6.2 .9 in the standard [10],

$M_{p l, N, R d}$ is the design plastic moment resistance of the cross-section composed of effective areas of flanges and fully effective web of cross-section without respect to cross-section classification reduced due to normal force $N_{E d}$ according to 6.2.9 in the standard [10].

The above presented calculation of $R F_{L M 71}$ should run using an iterative approach. Verifying the plastic resistance of welded cross-sections of classes 1 or 2 subjected to combination of bending, shear and normal force and their load-carrying capacities determination can be conservatively performed using equation (3), but the plastic resistances instead elastic ones should be used in equations (4) and (5). Verifying resistances of slender cross-sections of class 4 shall respect effects of the shear lag and plate buckling, which may be taken into account by means of effective crosssectional characteristics. Provisions given by 6.2.9.3 in the standard [10] and chapter 3 and 4 in the standard [11] should be respected. Load-carrying capacity of the slender cross-section subjected to bending, shear and normal force can be determined using equations (3), but the effective crosssectional characteristics should be substituted into equations (4) and (5) and possible shift of the centroid of the effective cross-sectional area $A_{\text {eff }}$ relative to the center of gravity of the gross crosssection according to 6.2.2.5 in the standard [10] shall be allowed for.

Buckling resistance of the compression member and resistance against lateral-torsional buckling of members subjected to major axis bending should be estimated in accordance with 6.3.1 and 6.3.2 in the standard [10]. The load-carrying capacities of those members may be determined by means of the following equations:

$$
\begin{aligned}
& R F_{L M 71}=\left(N_{b, R d}-N_{r s, E d}\right) / \mathrm{N}_{L M 71, E d}, R F_{L M 71}=\left(M_{b, R d}-M_{r s, E d}\right) / \mathrm{M}_{L M 71, E d}, \text { where } \\
& N_{b, R d}=\chi A \cdot f_{y} / \gamma_{M 1}, \quad M_{b, R d}=\chi_{L T} W \cdot f_{y} / \gamma_{M 1},
\end{aligned}
$$

where $\chi$ is the reduction factor for the relevant buckling mode of the flexural buckling and $\chi_{L T}$ is the reduction factor for lateral-torsional buckling. To determine the load-carrying capacity of the member subjected to compression and biaxial bending, the condition of reliability verification in accordance with 6.3.3 and Annex B valid for method 2 in the standard [10] shall be applied. An iterative approach should be applied to determine the load-carrying capacity of this member. 


\section{Conclusions}

The new Guideline for determination of railway bridge load-carrying capacity is introduced in this paper. Therefore, the paper presents brief description of general parts of the new Guideline and it also pays attention to the methodology of estimation of load-carrying capacities of steel bridge structural members and their cross-sections.

\section{Acknowledgement}

The paper presents results of the research project APVV-14-0772 supported by the Slovak Research and Development Agency and the project SK-PL-2015-0004 in frame of bilateral cooperation.

\section{References}

[1] VIČAN, J. et al.: Determination of load carrying capacity of railway bridges, Guideline of Railways of the Slovak Republic, 2015 (in Slovak).

[2] STN EN 1991-2, Eurocode 1: Actions on structures, Part 2: Traffic loads on bridges, Slovak Office of Standards, Metrology and Testing, 2006.

[3] STN EN 15528: Railway applications - Line categories for managing the interface between load limits of vehicles and infrastructure, Slovak Office of Standards, Metrology and Testing, 2013.

[4] STN EN 1991, Eurocode 1: Actions on structures, Part 1-1: General actions. Densities, selfweight, imposed loads for buildings, Slovak Office of Standards, Metrology and Testing, 2007.

[5] STN EN 1990, Eurocode: Basis of design, Slovak Office of Standards, Metrology and Testing, 2009.

[6] STN ISO 13822 Bases for design of structures, Assessment of existing structures. Slovak Office of Standards, Metrology and Testing, 2012.

[7] KOTEŠ, P. - VIČAN, J.: Recommended reliability levels for evaluation of existing bridges according to Eurocodes. In: Structural Engineering International, Vol. 23 (2013), p. 411 - 417.

[8] KOTEŠ, P. - VIČAN, J.: Reliability Levels for Existing Bridges Evaluation According to Eurocodes. In: Procedia Engineering, Vol. 40, 2012, p. $211-216$.

[9] CREMONA, C. : Assessment of existing structures in France: Standard and advanced practices, Bridge Maintenance, Safety, Management and Life Extension - Chen, Frangopol \& Ruan (Eds), 2014 Taylor \& Francis Group, London, 978-1-138-00103-9.

[10] STN EN 1993-1-1 Eurocode 3: Design of steel structures - Part 1-1: Design of steel structures, General rules and rules for buildings, Slovak Office of Standards, Metrology and Testing, 2006.

[11] STN EN 1993-1-5 Eurocode 3: Design of steel structures - Part 1-5: Plated structures, Slovak Office of Standards, Metrology and Testing, 2006.

[12] STN EN 1993-1-8 Eurocode 3: Design of steel structures - Part 1-8: Design of joints, Slovak Office of Standards, Metrology and Testing, 2007. 